\title{
Data Quality Issues With Physician-Rating Websites: Systematic Review
}

Pavankumar Mulgund $^{1}$, PhD; Raj Sharman ${ }^{1}$, PhD; Priya Anand ${ }^{2 *}$, MS; Shashank Shekhar ${ }^{* *}$, MS; Priya Karadi ${ }^{2 *}$, MS

${ }^{1}$ School of Management, State University of New York Buffalo, Buffalo, NY, United States

${ }^{2}$ Institute of Computational and Data Sciences, State University of New York Buffalo, Buffalo, NY, United States

*these authors contributed equally

\section{Corresponding Author:}

Pavankumar Mulgund, $\mathrm{PhD}$

School of Management

State University of New York Buffalo

160 Jacobs Management Center

Buffalo, NY

United States

Phone: 17167481552

Email:pmulgund@buffalo.edu

\section{Abstract}

Background: In recent years, online physician-rating websites have become prominent and exert considerable influence on patients' decisions. However, the quality of these decisions depends on the quality of data that these systems collect. Thus, there is a need to examine the various data quality issues with physician-rating websites.

Objective: This study's objective was to identify and categorize the data quality issues afflicting physician-rating websites by reviewing the literature on online patient-reported physician ratings and reviews.

Methods: We performed a systematic literature search in ACM Digital Library, EBSCO, Springer, PubMed, and Google Scholar. The search was limited to quantitative, qualitative, and mixed-method papers published in the English language from 2001 to 2020.

Results: A total of 423 articles were screened. From these, 49 papers describing 18 unique data quality issues afflicting physician-rating websites were included. Using a data quality framework, we classified these issues into the following four categories: intrinsic, contextual, representational, and accessible. Among the papers, 53\% (26/49) reported intrinsic data quality errors, $61 \%$ (30/49) highlighted contextual data quality issues, 8\% (4/49) discussed representational data quality issues, and $27 \%$ (13/49) emphasized accessibility data quality. More than half the papers discussed multiple categories of data quality issues.

Conclusions: The results from this review demonstrate the presence of a range of data quality issues. While intrinsic and contextual factors have been well-researched, accessibility and representational issues warrant more attention from researchers, as well as practitioners. In particular, representational factors, such as the impact of inline advertisements and the positioning of positive reviews on the first few pages, are usually deliberate and result from the business model of physician-rating websites. The impact of these factors on data quality has not been addressed adequately and requires further investigation.

(J Med Internet Res 2020;22(9):e15916) doi: $10.2196 / 15916$

\section{KEYWORDS}

physician-rating websites; data quality issues; doctor ratings; reviews; data quality framework

\section{Introduction}

\section{Background}

With the proliferation of mobile devices and instantaneous access to data, electronic word of mouth (e-WOM) has become a force to be reckoned with, affecting many aspects of our lives, including the things we buy, the shows we watch, and the places where we stay, directly or indirectly. Such dependence on e-WOM is especially true in the context of choosing a physician, as consumers historically have relied on word of mouth, including personal recommendations [1]. A simple check on Google Trends showed that the phrase "doctors near me" is now searched almost nine times more than it was 5 years ago; 
therefore, it is not surprising to see a rise in the number and scope of physician-rating websites (PRWs), which are peer-to-peer information-sharing platforms that patients use to share reviews and ratings of their health care providers. National survey data indicated that one in six Americans consult online ratings [2]. More than $30 \%$ of consumers compare physicians online before choosing a provider [3]. Emphasizing the impact of PRWs, one study [4] noted that $35 \%$ of patients selected physicians based on good ratings, while $37 \%$ avoided physicians with bad ratings. Another study found that patients consult PRWs as their first step in choosing providers [5] and that $80 \%$ of users trust online physician ratings as much as personal recommendations. Millennials, who account for more than half of PRW consumers, were found to exhibit a different behavior when they were unhappy with their health care services [6]. People aged 65 years or above were more likely to complain to doctors directly, while people aged 18 to 24 years were more likely to tell their friends. This emphasizes the evolution of PRWs into a platform for open and honest communication.

Although PRWs are less popular compared with rating websites in other domains, such as fast-moving consumer goods and e-commerce, they have high potential for growth. However, PRWs historically have lagged behind user expectations $[7,8]$, and one of the contributing factors is end users' lack of confidence in the data quality of PRWs. Furthermore, such data quality issues assume high importance, as poor data quality could affect consumers' care choices adversely. Previous research has discussed individual issues in specific contexts [9-57]; however, there is a need for a study that presents a holistic perspective by investigating a comprehensive set of data quality issues found in PRWs. This study fills that literature gap by gleaning data quality issues from several previous studies and classifying them based on the data quality framework.

\section{Data Quality Framework}

We used a data quality framework developed by Wang and Strong [58] to classify data quality issues in PRWs. It was created by considering consumers' perspectives on data quality, which accommodates a broader definition of data quality. Consequently, Wang and Strong defined data quality as "data that are fit for use by data consumers." Furthermore, they empirically collected data quality attributes from consumers instead of determining these attributes theoretically or basing them on expert opinions to identify attributes that emerge from real consumers. They then used two-stage surveys and a two-phase sorting study to develop a hierarchical framework. They captured various data quality attributes, consolidated these attributes into dimensions, and distributed the dimensions across the following categories (Figure 1): intrinsic data quality (IQ), contextual data quality (CQ), representational data quality (RQ), and accessibility data quality (AQ).

IQ entails dimensions that are inherent to the nature of data, including accuracy, objectivity, reputation, and believability. While information system professionals typically have interpreted IQ to mean accuracy alone, consumers assess IQ broadly by considering other elements, such as reputation, objectivity, and believability of the source. CQ is a measure of data quality within the context of the task at hand. It includes dimensions, such as relevance, value addition, timeliness, and completeness, which are specific to a given situation. Together, RQ and AQ emphasize the role of systems that store the data. RQ underscores the importance of developing interfaces that concisely present data so that they are easy to understand and interpret. AQ focuses on making systems secure to ensure that data are safe and available only to relevant users. This framework also makes pragmatic sense, as consumers' view of "fit for use data" would include data that are accurate, objective, believable, obtained from a reputable source, relevant to a specific task at hand, easy to understand, and accessible to them.

We use this framework because, unlike other frameworks [59], it accommodates a much broader definition of data quality. In addition, researchers have used it to evaluate the data quality of several customer-centric products, such as online bookstores and auction sites [60]. It has also been used to study critical factors affecting consumer-purchase behaviors in shopping contexts [61]. In recent years, as e-WOM has gained considerable prominence, some studies have used this framework to examine the impact of data quality on e-WOM [62]. Previous studies have used it to categorize data quality issues with electronic health records [63]. Furthermore, it has been used to study information quality issues on websites in which users, not experts, generate content [64]. Such an end-user point of view is especially relevant to our research, as most shortlisted studies discussed data quality issues in PRWs from patients' perspective. 
Figure 1. Data quality framework adapted from Wang and Strong [58].

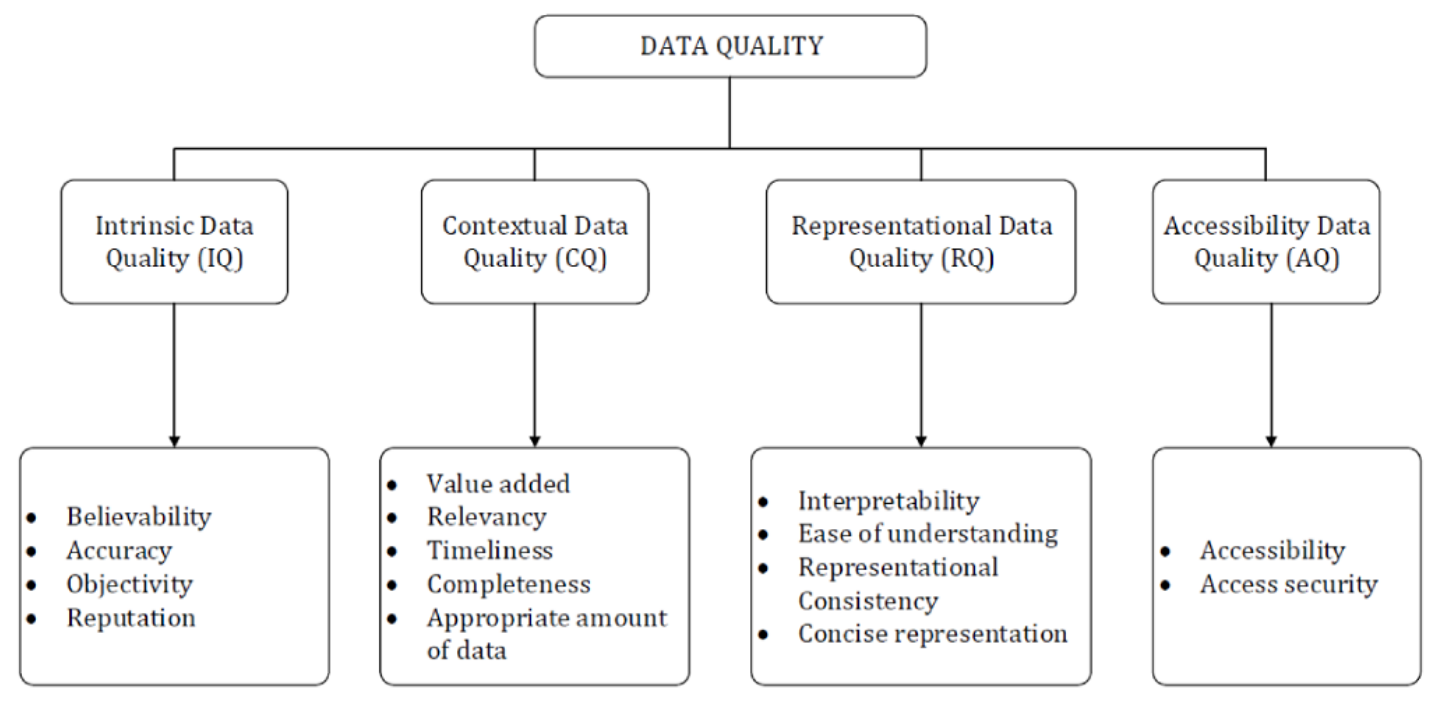

\section{Methods}

\section{Overview}

The study aimed to collect, analyze, and discuss data quality issues in PRWs based on the data quality framework of Wang and Strong. To accomplish this goal, we developed the following research questions:

- RQ1: What data quality issues exist in PRWs?
- $\quad$ RQ2: How are these data quality issues classified according to the Wang and Strong framework?

- RQ3: Which data quality issues have been addressed, and which ones warrant attention from researchers and practitioners?

Following the Preferred Reporting Items for Systematic Reviews and Meta-Analyses (PRISMA) guidelines [65,66], we performed a systematic literature review (Figure 2).

Figure 2. Literature search following the PRISMA guidelines. PRW: physician-rating website.

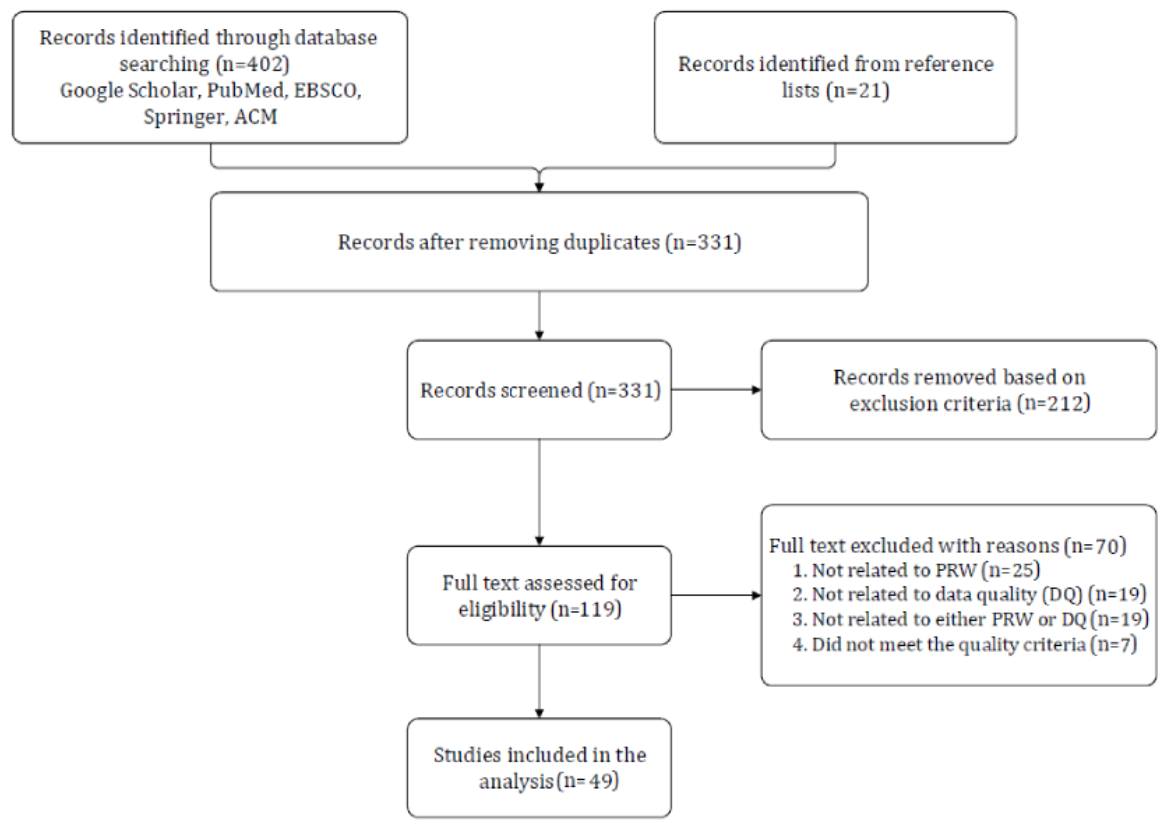

\section{Search Strategy}

We systematically searched for literature published in the past 20 years (between January 1, 2000, and January 1, 2020) using the following databases: ACM Digital Library, EBSCO, Springer, PubMed, and Google Scholar. The searches were performed using the following search terms: ("physician" OR “doctor" OR "provider") AND ("review” OR "rating”) AND (“online" OR “internet”) AND (“data" OR "quality"). Initially, title, abstract, and index terms were used to screen for published journal articles, conference papers, proceedings, case studies, and book chapters. Two reviewers performed the screening independently. The reviewers met on a regular basis to discuss the inclusion of studies. A third reviewer was consulted when there was disagreement between the reviewers. Furthermore, the reviewers performed hierarchical searches by identifying literature sources through references cited in the shortlisted papers selected from the keyword searches to find additional relevant articles. 


\section{Inclusion and Exclusion Criteria}

Physician quality is an elusive concept to measure, as it means different things to different stakeholders. Health care professionals and policymakers have developed a plethora of clinical and process-quality measures to address the challenge of evaluating physician quality. Some well-known examples of such quality indicators include the risk-adjusted mortality rate [67], 30-day readmission rate [68], and percentage of patients receiving recommended preventive care. Although such clinical measures of quality are critical to improving the quality of care, they emphasize the process of care, not individual physicians' quality. Furthermore, these measures are neither easy to access nor simple to understand. They also do not place high emphasis on patients' perceptions of care quality. Owing to this lack of agreed-upon, meaningful, and readily available objective data on individual clinician performance, patients end up relying on other patients for recommendations.

PRWs fill this void by providing a platform on which patients can evaluate physicians based on their experiences; however, these ratings and reviews are individual patients' subjective opinions and may not be indicative of physicians' clinical quality. Thus, it is possible that a poorly rated physician has provided the correct or best treatment. Some studies argue that patients are not well-suited to evaluate physician quality because of the information asymmetry between patients and care providers [69]. In addition, several studies emphasize that ratings and reviews of patients are not correlated to clinical measures of physician quality [70,71]. Despite these shortcomings, PRWs have surged in popularity and have become instrumental in shaping prospective patients' opinions. Individuals also use them to make crucial decisions, such as selecting a provider, because just as in any other consumer service business, customers' perceptions impact revenue.

Therefore, in this paper, we focused on physician quality from patients' perspectives, as captured by PRWs. Prior studies that examined data quality of patient-reported reviews and ratings were included in this literature review. Studies were excluded from this review if they (1) focused primarily on clinical quality measures that health care providers or public health agencies reported; (2) examined data quality issues that are not related to public PRWs (eg, papers that catered to paid websites, such as Castle Connolly, were excluded from this review); (3) were not available as full text in the final search; (4) were not written in English; and (5) were white papers, reports, abstracts only, letters, or commentaries.

\section{Data Extraction, Synthesis, and Evaluation}

A Google document was created for data extraction. For each chosen study, the data collected included the title, author, year, country, abstract, study type, and number of participants. We assessed the selected studies' quality based on the criteria listed in Table 1 . The quality criteria were developed using guidelines specified by the Cochrane Handbook for Systematic Reviews [72] and the report "Guidelines for performing systematic literature reviews in software engineering" [73]. Two reviewers independently assessed every included study by assigning "Yes," "No," or "Cannot tell" scores to each criterion. Only studies that received a "Yes" on all criteria were included in this review. A senior researcher was consulted for a resolution if there was disagreement between the reviewers.

Table 1. Quality criteria for the included studies.

\begin{tabular}{ll}
\hline Identifier & Issue \\
\hline C1 & Does the article clearly show the purpose of the research? \\
C2 & Does the article adequately provide the literature review, background, or context? \\
C3 & Does the article present the related work with regard to the main contribution? \\
C4 & Does the article have a clear description of the research methodology? \\
C5 & Does the article include research results? \\
C6 & Does the article present a conclusion related to the research objectives? \\
C7 & Does the article recommend future research directions or improvements? \\
\hline
\end{tabular}

\section{Results}

\section{Characteristics of Reviewed Studies}

We included 49 papers published between 2009 and 2019. Among these, 28 articles were identified through the initial search and additional 21 articles meeting the study criteria were identified by reviewing the reference lists of those articles. The list of included papers is presented in Multimedia Appendix 1. We identified 18 unique data quality issues that afflict PRWs and classified these issues into four categories based on the data quality framework. In recent years, PRWs have captured the research community's attention as evidenced by a surge in publications in the past 5 years. More than 71\% (35/49) of the papers used quantitative methods to test their research hypotheses, $22 \%(11 / 49)$ adopted qualitative methods, and $6 \%$ (3/49) leveraged mixed methods. Healthgrades $(n=12)$, RateMDs $(n=8)$, Vitals $(n=7)$, and Jameda $(n=4)$ were the most targeted PRWs, while other sites, such as Zocdoc, Press Ganey, and Healthcare Reviews, were not examined as much. Three studies compared PRWs with business directory and review sites such as Yelp. In addition, several studies collected data from multiple PRWs to compare their results across different rating websites. Altogether, 26 articles focused on issues relating to IQ, while 30 discussed CQ concerns. Four articles emphasized RQ errors, and 13 were related to AQ challenges. Around half (26/49) the included studies focused on more than one type of data quality issue. 


\section{Discussion}

\section{Principal Findings}

Consistent with this study's goals, we discuss different data quality issues in a narrative format based on the four types of issues specified in the data quality framework.

\section{IQ Issues}

As presented in Table 2, we discuss intrinsic data quality issues based on the following dimensions: accuracy, objectivity, believability, and reputation. The main hurdle affecting the accuracy of reviews and rating data was the glaring absence of negative ratings. A prior study highlighted the absence of negative ratings by empirically showing that physicians with low patient-perceived quality were less likely to be rated. Although a positive correlation between online ratings and physician quality was found, the association was the strongest for the medium segment. While the ratings were not sensitive for high-quality physicians, there were fewer ratings for physicians at the lower end of the quality distribution [9].

Another study showed the presence of ubiquitous high ratings for interventional radiologists, with mean ratings ranging from 4.3 to 4.5 on a five-point scale [10]. This lack of negative ratings was not only limited to interventional radiologists, but also spanned other medical specialties. Several studies corroborated this finding by noting that the average physician rating across all specialties was consistently very positive [11-16]. Sparse negative ratings could also be attributed to legal restrictions on entering negative feedback in some countries, such as Switzerland. However, this dearth of negative ratings adversely affects overall opinions about data quality greatly.

Table 2. Intrinsic data quality issues.

\begin{tabular}{|c|c|c|}
\hline Issues & Dimension & Citations \\
\hline Ratings were either positive or extremely positive, with a notable absence of negative ratings. & Accuracy and objectivity & [9-16] \\
\hline $\begin{array}{l}\text { A significant number of ratings contained extreme values, typically in the form of a dichotomous distri- } \\
\text { bution of the minimum and maximum values. }\end{array}$ & Objectivity & {$[9,17-19]$} \\
\hline $\begin{array}{l}\text { A significant number of reviews contained emotionally charged comments, implying a lack of objectiv- } \\
\text { ity in the reviews. }\end{array}$ & Objectivity & {$[20-22]$} \\
\hline $\begin{array}{l}\text { Online ratings were less sensitive to physician quality at the high end of quality distribution, implying } \\
\text { the presence of the halo effect. }\end{array}$ & Objectivity & {$[9,23,24]$} \\
\hline $\begin{array}{l}\text { Some physician-rating websites did not ensure ratings' accuracy by allowing anonymous ratings that } \\
\text { were not entirely believable. }\end{array}$ & Believability & {$[18,20,25,26]$} \\
\hline Some sites allowed premium-paying physicians to hide up to three negative comments. & Believability and reputation & {$[18,27,28]$} \\
\hline $\begin{array}{l}\text { Physicians were more likely to trust patient-experience surveys that health systems issued, whereas patients } \\
\text { were more likely to trust ratings found on independent websites. }\end{array}$ & The data source's reputation & {$[29]$} \\
\hline
\end{tabular}

Several research studies [9,17-19] questioned the objectivity of review and rating data by uncovering the high presence of extreme ratings, such as one- or five-star ratings. Extreme ratings do not represent a balanced view and are usually an impulsive response to an emotional trigger. Other studies [20-22] further corroborated these findings by revealing the presence of emotionally charged review comments. On one hand, physicians with low perceived quality were hardly rated; thus, a single negative review had a disproportionate impact on the overall rating. On the other hand, physicians with several reviews incurred no relevant impact from a negative rating on overall numbers owing to relatively few negative ratings. Two studies also highlighted the presence of the halo effect $[23,24]$. One found that higher ratings were associated with marketing strategies that the physicians employed. It also discovered that physicians' online presence greatly impacted their ratings. This phenomenon demonstrates the susceptibility of reviews and ratings to external factors, such as marketing and promotion, casting serious doubt on the credibility of the data.

Other studies $[18,20,25]$ examined data quality challenges that emerge when users can rate physicians anonymously. Anonymity exposes information to manipulation from sources such as competition, slanderers, and biased friends. The effect of anonymous ratings cascades into a relevant issue when the number of genuine negative ratings is small, as is the case with PRWs. An excellent example of such abuse of PRWs is found in how antiabortion groups deliberately target physicians working in abortion clinics with libelous comments and negative ratings under the veneer of anonymity [26].

Several business models of PRWs also skew the believability of ratings and review information by providing physicians with premium subscriptions having an option to hide up to three negative comments $[27,28]$. The hidden negative reviews may mislead consumers who are usually unaware of the business models of PRWs. Several researchers also questioned the ethics of hiding up to three negative ratings when, on average, there were less than three negative physician ratings [18].

\section{RQ Issues}

As presented in Table 3, RQ emphasizes clear representation and includes dimensions such as interpretability, ease of understanding, representational consistency, and conciseness. Of all data quality issues, the ones related to RQ are the most insidious, as even an accurate data set can lead to misleading conclusions if representation is not appropriate. One study observed how users can be influenced by the mere repositioning of positive reviews to the first few pages, as most users read initial reviews more than subsequent ones. The same study 
examined the negative impact of placing poor ratings at the top of the profile page [25]. Furthermore, researchers have argued that the five-point scale that PRWs use is an imperfect proxy for physician quality [30,31] as the difference between a rating of 4.8 and 4.9 might be too small to be meaningful from an end user's perspective. These RQ issues seem to be more deliberate than the other data issues and result from the business or revenue model of PRWs. Thus, they may be more challenging to overcome.

Table 3. Representational data quality issues.

\begin{tabular}{ll}
\hline Issues & Dimension \\
\hline $\begin{array}{l}\text { The five-point scale used for measuring physician quality did not have the finer granularity needed to } \\
\text { highlight the minor differences in physician quality. }\end{array}$ & Interpretability \\
$\begin{array}{l}\text { The positioning of positive reviews and rating data on the first few pages greatly impacted patient per- } \\
\text { ceptions. }\end{array}$ & $\begin{array}{l}\text { Representational consisten- } \\
\text { cy }\end{array}$ \\
$\begin{array}{l}\text { Every physician-rating website used different underlying scales to measure the effectiveness of the } \\
\text { physicians. Therefore, interpreting results across different physicians can be difficult. }\end{array}$ & Interpretability \\
\hline
\end{tabular}

\section{CQ Issues}

As presented in Table 4, CQ examines issues in the context of the task at hand. For this paper, the task is assumed to be patient decision making in terms of choosing a provider by analyzing ratings and reviews. Several data quality issues plagued this dimension. The most fundamental concern stemmed from the need for an appropriate amount of data to make meaningful decisions. One critical issue in this segment was the nonexistence of ratings and reviews for most of the physicians. Several papers [22,23,33-37] found that more than half of the physicians had no ratings or reviews. They also argued that no meaningful decisions could be made with the unavailability of data for such a considerable volume of physicians. Another related threat to CQ was the low volume of reviews and ratings. One study [23] noted that $57 \%$ of the doctors received only one to three ratings. Such low volumes cast doubts on the ratings' credibility, especially when sites allow anonymous ratings. Previous research showed that users did not trust the rating and review data, and sought information from alternative sources until a minimum number of ratings was available. Thus, it should come as no surprise that multiple prior studies on e-WOM in other domains, such as e-commerce, found that high volumes lend more credence to rating and review data. Furthermore, data analysis showed that early negative reviews beget more negative reviews [25]. At the same time, doctors with great initial reviews might continue to benefit from these reviews, even if their clinical quality has declined over the years.

A nuanced challenge to CQ emerged from the underlying factors used to compute ratings and reviews. One study [51] compared the factors between two sites, one from the United States and another from Germany. They found that German PRWs focused on parameters that measure physician characteristics, while American sites focused on the entire clinical process, including registration, clinical pathways, and staff behaviors. Typically, most PRWs include wait times, staff behaviors, follow-ups, and ease of making appointments, some of which are not under physicians' direct control. In addition, these factors may not be truly representative of physician quality. Some studies suggested taking reviews and ratings with a "grain of salt," as the ratings reflected patients' perceptions and did not objectively measure physician quality.

Furthermore, patients might not be able to assess a wide range of physician attributes owing to information asymmetry between physicians and patients. Some studies have discussed the possibilities of bringing both patient perspectives and clinical quality measures together to enhance CQ [38]. The ease of decision-making from a user's perspective defines the essence of CQ. Such a user perspective was affected adversely when a low degree of correlation existed among different physician review websites [44,48-51], as users may not know which websites to trust.

Table 4. Contextual data quality issues.

\begin{tabular}{|c|c|c|}
\hline Issues & Dimension & Citations \\
\hline $\begin{array}{l}\text { There was a low volume of reviews and ratings, with more than half the physicians having less } \\
\text { than one to three ratings. }\end{array}$ & Appropriate amount of data & {$[22,23,33-37]$} \\
\hline $\begin{array}{l}\text { Physician-rating websites captured patient perceptions of physician quality; they did not capture } \\
\text { and present objective measures of quality, such as Physician Quality Reporting System (PQRS) } \\
\text { ratings for physicians or risk-adjusted mortality rate. }\end{array}$ & Objectivity completeness & {$[29,31,38,39]$} \\
\hline $\begin{array}{l}\text { Higher ratings were associated with marketing strategies that physicians employed, such as sig- } \\
\text { nificant online presence and promotion of satisfied patients' reviews. }\end{array}$ & Objectivity relevance & {$[40,43,47]$} \\
\hline There was a low degree of correlation among online websites on surgeon ratings. & Value addition & {$[44,48-51]$} \\
\hline
\end{tabular}




\section{AQ Issues}

As presented in Table 5, AQ focuses on the dimensions ease of access and security of access. While PRWs are afflicted by only a limited set of accessibility challenges, some issues warrant further discussion. First, while the internet may be accessible universally, we must consider socioeconomic and psychographic barriers to the accessibility of PRWs [53]. Typically, tech-savvy people with reasonable income and education use PRWs. Several studies noted that PRWs did not represent the opinions of elderly people, who comprise the largest consumer segment for health care services. Second, the number of ratings and reviews that physicians received depended on their specialty. One study noted that physicians in specialties that warranted high interaction with patients, such as obstetrics and gynecology, were more likely to be rated, while other specialties, such as pathology, were less likely to be rated [54].

Several studies found that the maturity level of PRWs was not uniform across countries. While PRWs have been adopted widely in the United States, the United Kingdom, and Canada, they were at an early stage of adoption in other countries, such as Australia [34], Switzerland [55], Lithuania [56], and Germany [57]. Data quality issues with PRWs in these countries were more pronounced when compared with other nations. Furthermore, accessibility issues emerged owing to legal and regulatory challenges. For instance, Switzerland provides physicians with a legal option to have negative reviews deleted.

Table 5. Accessibility data quality issues.

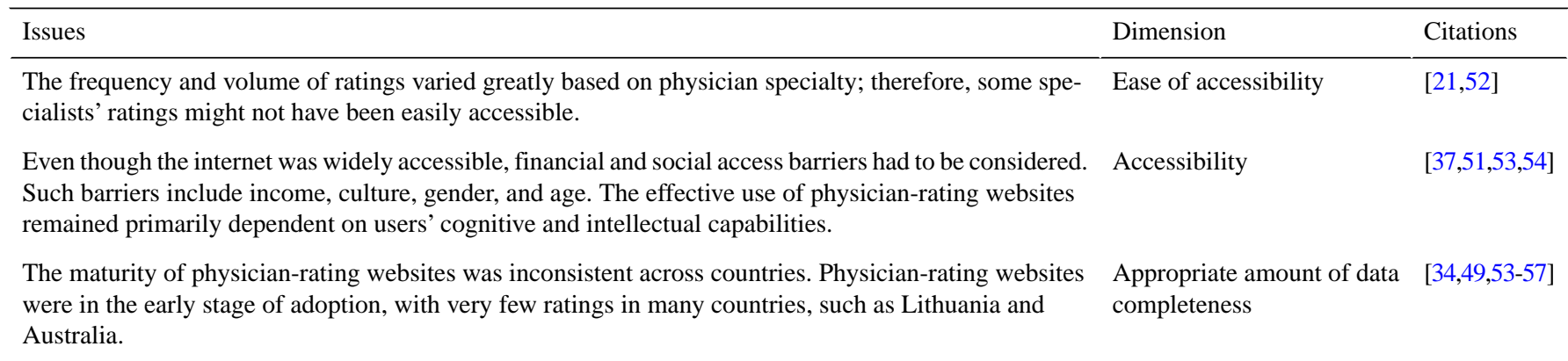

\section{Opportunities for Future Research}

In this review, the key observation was the lack of emphasis on $\mathrm{RQ}$ and $\mathrm{AQ}$ issues in prior research. Most studies highlighted IQ and CQ issues, which are foundational to achieving other types of data quality. Although the number of papers published on RQ [30-32] and AQ [55-57] issues has increased in recent years, more research is warranted on these issues.

Specifically, the misleading impact of inline advertisements and the effect from framing reviews differently warrant further investigation. Furthermore, while the application of data analytic methods has surged considerably, there is a conspicuous absence of studies that have examined the impact of different kinds of visualizations of rating and review data on patient decision-making. Similarly, machine learning and predictive analytic methods could well be used to forecast future physician ratings. Such studies could educate physicians further on strategies to improve their future ratings. Another observation is the need to examine the impact of physician reviews and ratings on providers' revenue or insurance payments. Understanding this impact can help explain physicians' behaviors and motivations.

Relatively few studies have discussed the use of data analytics, machine learning, and other statistical methods to identify and distinguish fake reviews from genuine ones. The development of such mechanisms can substantially enhance the quality of review and rating data. Further, data privacy laws, such as General Data Protection Regulation (GDPR), can potentially impact the quality of review and rating data adversely. More research is warranted to examine the impact of these regulations on accessibility data quality.

\section{Limitations}

This systematic review has several limitations. The first is associated with the methodology used to select studies. Relatively few $(n=49)$ studies were included, based on the selection criteria that the authors set. Five databases were searched to select studies. Other databases potentially could have yielded additional studies. Furthermore, while the authors performed due diligence in execution, the search was limited to the set of selected keywords. It is possible that some relevant studies were not identified owing to keyword mismatches or title differences and, therefore, were not included in the review.

Second, we only included articles written in the English language, and business models can vary greatly among geographical locations, depending on existing practices, cultures, and regulations. We tried to find literature from diverse geographical areas, but few studies were accessible to us owing to limitations caused by language barriers and the extent of research in other geographical areas. Furthermore, we did not include non-peer-reviewed sources, such as white papers and dissertations. It is possible that relevant information from such sources could have influenced our findings.

\section{Conclusion}

This paper contributes to a better understanding of data quality issues in PRWs by highlighting several vital challenges that these issues pose. The paper acknowledges the tremendous potential that PRWs have in transforming health care by being the voice of consumers and increasing the transparency of health care processes. However, this study showed that data quality challenges present relevant hurdles to the realization of these benefits. The impact of these data quality issues will only surge as millennials base their decisions on PRW data. 
Historically, IQ and CQ factors have been principal sources of data quality issues, and many researchers have studied them extensively. However, RQ and AQ factors warrant more research. In particular, RQ factors, such as the impact of inline advertisements and the positioning of positive reviews on the first few pages, are usually deliberate and result from the business or revenue model of PRWs. In addition, data privacy regulations, such as GDPR in the European Union and California Consumer Privacy Act (CCPA) in California, may greatly impact PRWs. More research is needed to understand their implications. Furthermore, the effect of cultural factors (eg, in some cultures, speaking negatively about authority figures is viewed as inappropriate), though relevant, was not considered, as it is under-addressed in the literature. Future innovations and research are needed to address these emerging data quality issues. We hope that this study's results inspire professionals and researchers to develop PRWs that are more robust and do not have many data quality issues.

\section{Conflicts of Interest}

None declared.

\section{Multimedia Appendix 1}

List of all included studies.

[XLSX File (Microsoft Excel File), 33 KB-Multimedia Appendix 1]

\section{References}

1. Tu H, Lauer J. Word of mouth and physician referrals still drive health care provider choice. Res Brief 2008 Dec(9):1-8. [Medline: 19054900$]$

2. Fox S. Vagal afferent controls of feeding: a possible role for gastrointestinal BDNF. Clin Auton Res 2013 Feb;23(1):15-31. [doi: 10.1007/s10286-012-0170-x] [Medline: 22717678]

3. Fox S, Purcell K. Chronic Disease and the Internet. Pew Research Center. 2010. URL: https://www.pewresearch.org/internet/ 2010/03/24/chronic-disease-and-the-internet/ [accessed 2020-09-21]

4. Hanauer DA, Zheng K, Singer DC, Gebremariam A, Davis MM. Public awareness, perception, and use of online physician rating sites. JAMA 2014 Feb 19;311(7):734-735. [doi: 10.1001/jama.2013.283194] [Medline: 24549555]

5. Findlay SD. Consumers' Interest In Provider Ratings Grows, And Improved Report Cards And Other Steps Could Accelerate Their Use. Health Aff (Millwood) 2016 Apr;35(4):688-696. [doi: 10.1377/hlthaff.2015.1654] [Medline: 27044970]

6. Ellimoottil C, Leichtle S, Wright C, Fakhro A, Arrington A, Chirichella T, et al. Online physician reviews: the good, the bad and the ugly. Bull Am Coll Surg 2013 Sep;98(9):34-39. [Medline: 24455818]

7. Bidmon S, Elshiewy O, Terlutter R, Boztug Y. What Patients Value in Physicians: Analyzing Drivers of Patient Satisfaction Using Physician-Rating Website Data. J Med Internet Res 2020 Feb 03;22(2):e13830 [FREE Full text] [doi: 10.2196/13830] [Medline: 32012063]

8. Murphy GP, Radadia KD, Breyer BN. Online physician reviews: is there a place for them? RMHP 2019 May; Volume 12:85-89. [doi: 10.2147/rmhp.s170381]

9. Gao GG, McCullough JS, Agarwal R, Jha AK. A changing landscape of physician quality reporting: analysis of patients' online ratings of their physicians over a 5-year period. J Med Internet Res 2012 Feb 24;14(1):e38 [FREE Full text] [doi: 10.2196/jmir.2003] [Medline: 22366336]

10. Kadry B, Chu LF, Kadry B, Gammas D, Macario A. Analysis of 4999 online physician ratings indicates that most patients give physicians a favorable rating. J Med Internet Res 2011 Nov 16;13(4):e95 [FREE Full text] [doi: 10.2196/jmir.1960] [Medline: 22088924]

11. Emmert M, Meier F. An analysis of online evaluations on a physician rating website: evidence from a German public reporting instrument. J Med Internet Res 2013 Aug 06;15(8):e157 [FREE Full text] [doi: 10.2196/jmir.2655] [Medline: 23919987]

12. Emmert M, Halling F, Meier F. Evaluations of dentists on a German physician rating Website: an analysis of the ratings. J Med Internet Res 2015 Jan 12;17(1):e15 [FREE Full text] [doi: 10.2196/jmir.3830] [Medline: 25582914]

13. Black E, Thompson L, Saliba H, Dawson K, Black NM. An analysis of healthcare providers' online ratings. Inform Prim Care 2009 Dec 01;17(4):249-253 [FREE Full text] [doi: 10.14236/jhi.v17i4.744] [Medline: 20359403]

14. Orhurhu MS, Chu R, Claus L, Roberts J, Salisu B, Urits I, et al. Neuropathic Pain and Sickle Cell Disease: a Review of Pharmacologic Management. Curr Pain Headache Rep 2020 Jul 24;24(9):52-86. [doi: 10.1007/s11916-020-00885-5] [Medline: 32705357]

15. Kirkpatrick W, Abboudi J, Kim N, Medina J, Maltenfort M, Seigerman D, et al. An Assessment of Online Reviews of Hand Surgeons. Arch Bone Jt Surg 2017 May;5(3):139-144 [FREE Full text] [Medline: 28656160]

16. López A, Detz A, Ratanawongsa N, Sarkar U. What patients say about their doctors online: a qualitative content analysis. J Gen Intern Med 2012 Jun 4;27(6):685-692 [FREE Full text] [doi: 10.1007/s11606-011-1958-4] [Medline: 22215270]

17. Pike CW, Zillioux J, Rapp D. Online Ratings of Urologists: Comprehensive Analysis. J Med Internet Res 2019 Jul 02;21(7):e12436 [FREE Full text] [doi: 10.2196/12436] [Medline: 31267982] 
18. Samora JB, Lifchez SD, Blazar PE, American Society for Surgery of the Hand EthicsProfessionalism Committee. Physician-Rating Web Sites: Ethical Implications. J Hand Surg Am 2016 Jan;41(1):104-10.e1. [doi: 10.1016/j.jhsa.2015.05.034] [Medline: 26304734]

19. Mostaghimi A, Crotty BH, Landon BE. The availability and nature of physician information on the internet. J Gen Intern Med 2010 Nov;25(11):1152-1156 [FREE Full text] [doi: 10.1007/s11606-010-1425-7] [Medline: 20544300]

20. Wallace BC, Paul MJ, Sarkar U, Trikalinos TA, Dredze M. A large-scale quantitative analysis of latent factors and sentiment in online doctor reviews. J Am Med Inform Assoc 2014;21(6):1098-1103 [FREE Full text] [doi: 10.1136/amiajnl-2014-002711] [Medline: 24918109]

21. Carbonell G, Brand M. Choosing a Physician on Social Media: Comments and Ratings of Users are More Important than the Qualification of a Physician. International Journal of Human-Computer Interaction 2017 Aug 03;34(2):117-128. [doi: 10.1080/10447318.2017.1330803]

22. Kizawa Y. Leveraging online patient reviews to improve quality of care: art-specific insights for practice administrators and physicians. Fertility and Sterility 2017 Sep;108(3):e112. [doi: 10.1016/j.fertnstert.2017.07.343]

23. Hao H, Zhang K, Wang W, Gao G. A tale of two countries: International comparison of online doctor reviews between China and the United States. Int J Med Inform 2017 Mar;99:37-44. [doi: 10.1016/j.ijmedinf.2016.12.007] [Medline: 28118920]

24. Obele CC, Duszak R, Hawkins CM, Rosenkrantz AB. What Patients Think About Their Interventional Radiologists: Assessment Using a Leading Physician Ratings Website. J Am Coll Radiol 2017 May;14(5):609-614. [doi: 10.1016/j.jacr.2016.10.013] [Medline: 28017529]

25. Li S, Feng B, Chen M, Bell RA. Physician review websites: effects of the proportion and position of negative reviews on readers' willingness to choose the doctor. J Health Commun 2015 Apr;20(4):453-461. [doi: 10.1080/10810730.2014.977467] [Medline: 25749406]

26. Davis MM, Hanauer DA. Online Measures of Physician Performance: Moving Beyond Aggregation to Integration. JAMA 2017 Jun 13;317(22):2325-2326. [doi: 10.1001/jama.2017.3979] [Medline: 28609521]

27. Merrell JG, Levy BH, Johnson DA. Patient assessments and online ratings of quality care: a "wake-up call" for providers. Am J Gastroenterol 2013 Nov;108(11):1676-1685. [doi: 10.1038/ajg.2013.112] [Medline: 24192941]

28. Gordon HS. Consider Embracing the Reviews from Physician Rating Websites. J Gen Intern Med 2017 Jun;32(6):599-600 [FREE Full text] [doi: 10.1007/s11606-017-4036-8] [Medline: 28299603]

29. Haskins IN, Krpata DM, Rosen MJ, Perez AJ, Tastaldi L, Butler RS, et al. Online Surgeon Ratings and Outcomes in Hernia Surgery: An Americas Hernia Society Quality Collaborative Analysis. J Am Coll Surg 2017 Nov;225(5):582-589. [doi: 10.1016/j.jamcollsurg.2017.08.007] [Medline: 28838868]

30. Murphy GP, Awad MA, Osterberg EC, Gaither TW, Chumnarnsongkhroh T, Washington SL, et al. Web-Based Physician Ratings for California Physicians on Probation. J Med Internet Res 2017 Aug 22;19(8):e254 [FREE Full text] [doi: 10.2196/jmir.7488] [Medline: 28830852]

31. Meszmer N, Jaegers L, Schöffski O, Emmert M. [Do online ratings reflect structural differences in healthcare? The example of German physician-rating websites]. Z Evid Fortbild Qual Gesundhwes 2018 Apr;131-132:73-80. [doi: 10.1016/j.zefq.2017.11.007] [Medline: 29331281]

32. Rothenfluh F, Schulz PJ. Content, Quality, and Assessment Tools of Physician-Rating Websites in 12 Countries: Quantitative Analysis. J Med Internet Res 2018 Jun 14;20(6):e212 [FREE Full text] [doi: 10.2196/jmir.9105] [Medline: 29903704]

33. Carbonell G, Meshi D, Brand M. The Use of Recommendations on Physician Rating Websites: The Number of Raters Makes the Difference When Adjusting Decisions. Health Commun 2019 Nov;34(13):1653-1662. [doi: 10.1080/10410236.2018.1517636] [Medline: 30222006]

34. Atkinson S. Current status of online rating of Australian doctors. Aust. J. Prim. Health 2014;20(3):222. [doi: 10.1071/py14056]

35. McLennan S, Strech D, Reimann S. Developments in the Frequency of Ratings and Evaluation Tendencies: A Review of German Physician Rating Websites. J Med Internet Res 2017 Aug 25;19(8):e299 [FREE Full text] [doi: 10.2196/jmir.6599] [Medline: 28842391]

36. McLennan S, Strech D, Kahrass H. Why are so few patients rating their physicians on German physician rating websites? A qualitative study. BMC Health Serv Res 2018 Aug 29;18(1):670 [FREE Full text] [doi: 10.1186/s12913-018-3492-0] [Medline: 30157842]

37. Gilbert K, Hawkins CM, Hughes DR, Patel K, Gogia N, Sekhar A, et al. Physician rating websites: do radiologists have an online presence? J Am Coll Radiol 2015 Aug;12(8):867-871. [doi: 10.1016/j.jacr.2015.03.039] [Medline: 26250980]

38. Bardach NS, Asteria-Peñaloza R, Boscardin WJ, Dudley RA. The relationship between commercial website ratings and traditional hospital performance measures in the USA. BMJ Qual Saf 2013 Mar;22(3):194-202 [FREE Full text] [doi: 10.1136/bmjqs-2012-001360] [Medline: 23178860]

39. Gray BM, Vandergrift JL, Gao G, McCullough JS, Lipner RS. Website ratings of physicians and their quality of care. JAMA Intern Med 2015 Feb;175(2):291-293. [doi: 10.1001/jamainternmed.2014.6291] [Medline: 25437252]

40. Trehan SK, DeFrancesco CJ, Nguyen JT, Charalel RA, Daluiski A. Online Patient Ratings of Hand Surgeons. J Hand Surg Am 2016 Jan;41(1):98-103. [doi: 10.1016/j.jhsa.2015.10.006] [Medline: 26710742] 
41. Donnally CJ, Roth ES, Li DJ, Maguire JA, McCormick JR, Barker GP, et al. Analysis of Internet Review Site Comments for Spine Surgeons. SPINE 2018;43(24):1725-1730. [doi: 10.1097/brs.0000000000002740]

42. Saifee D, Bardhan I, Zheng Z. Do Online Reviews of Physicians Reflect Healthcare Outcomes? In: Chen H, Zeng D, Karahanna E, Bardhan I, editors. Smart Health. ICSH 2017. Lecture Notes in Computer Science. Cham: Springer; Jun 26, 2017:161-168.

43. Liu X, Guo X, Wu H, Vogel D. Doctor's Effort Influence on Online Reputation and Popularity. In: Zheng X, Zeng D, Chen H, Zhang Y, Xing C, Neill DB, editors. Smart Health. ICSH 2014. Lecture Notes in Computer Science. Cham: Springer; 2014:111-126.

44. Nwachukwu BU, Adjei J, Trehan SK, Chang B, Amoo-Achampong K, Nguyen JT, et al. Rating a Sports Medicine Surgeon's "Quality" in the Modern Era: an Analysis of Popular Physician Online Rating Websites. HSS J 2016 Oct;12(3):272-277 [FREE Full text] [doi: 10.1007/s11420-016-9520-x] [Medline: 27703422]

45. Li S, Lee-Won RJ, McKnight J. Effects of Online Physician Reviews and Physician Gender on Perceptions of Physician Skills and Primary Care Physician (PCP) Selection. Health Commun 2019 Oct;34(11):1250-1258. [doi: 10.1080/10410236.2018.1475192] [Medline: 29792519]

46. Haug M, Gewald H. Are Friendly and Competent the Same?: The Role of the Doctor-Patient Relationship in Physician Ratings. In: SIGMIS-CPR'18: Proceedings of the 2018 ACM SIGMIS Conference on Computers and People Research. 2018 Jun Presented at: 2018 ACM SIGMIS Conference on Computers and People Research; June 18, 2018; Buffalo, New York p. 157. [doi: 10.1145/3209626.3209734]

47. Prabhu A, Randhawa S, Clump D, Heron D, Beriwal S. What Do Patients Think About Their Radiation Oncologists? An Assessment of Online Patient Reviews on Healthgrades. Cureus 2018 Feb 06;10(2):e2165 [FREE Full text] [doi: 10.7759/cureus.2165] [Medline: 29644154]

48. Calixto NE, Chiao W, Durr ML, Jiang N. Factors Impacting Online Ratings for Otolaryngologists. Ann Otol Rhinol Laryngol 2018 Aug;127(8):521-526. [doi: 10.1177/0003489418778062] [Medline: 29882425]

49. Patel S, Cain R, Neailey K, Hooberman L. Public Awareness, Usage, and Predictors for the Use of Doctor Rating Websites: Cross-Sectional Study in England. J Med Internet Res 2018 Jul 25;20(7):e243 [FREE Full text] [doi: 10.2196/jmir.9523] [Medline: $\underline{30045831]}$

50. McGrath RJ, Priestley JL, Zhou Y, Culligan PJ. The Validity of Online Patient Ratings of Physicians: Analysis of Physician Peer Reviews and Patient Ratings. Interact J Med Res 2018 Apr 09;7(1):e8 [FREE Full text] [doi: 10.2196/ijmr.9350] [Medline: 29631992]

51. Terlutter R, Bidmon S, Röttl J. Who uses physician-rating websites? Differences in sociodemographic variables, psychographic variables, and health status of users and nonusers of physician-rating websites. J Med Internet Res 2014 Mar 31;16(3):e97 [FREE Full text] [doi: 10.2196/jmir.3145] [Medline: 24686918]

52. Quigley DD, Elliott MN, Farley DO, Burkhart Q, Skootsky SA, Hays RD. Specialties differ in which aspects of doctor communication predict overall physician ratings. J Gen Intern Med 2014 Mar;29(3):447-454 [FREE Full text] [doi: 10.1007/s11606-013-2663-2] [Medline: 24163151]

53. Strech D. Ethical principles for physician rating sites. J Med Internet Res 2011 Dec 06;13(4):e113 [FREE Full text] [doi: 10.2196/jmir.1899] [Medline: 22146737]

54. Liu JJ, Matelski JJ, Bell CM. Scope, Breadth, and Differences in Online Physician Ratings Related to Geography, Specialty, and Year: Observational Retrospective Study. J Med Internet Res 2018 Mar 07;20(3):e76 [FREE Full text] [doi: 10.2196/jmir.7475] [Medline: 29514775]

55. McLennan S. Quantitative Ratings and Narrative Comments on Swiss Physician Rating Websites: Frequency Analysis. J Med Internet Res 2019 Jul 26;21(7):e13816 [FREE Full text] [doi: 10.2196/13816] [Medline: $\underline{31350838}$ ]

56. Bäumer F, Kersting J, Kur?elis V, Geierhos M. Rate Your Physician: Findings from a Lithuanian Physician Rating Website. In: Damaševičius R, Vasiljevienė G, editors. Information and Software Technologies. ICIST 2018. Communications in Computer and Information Science. Cham: Springer; Oct 2018:43-58.

57. McLennan S, Strech D, Meyer A, Kahrass H. Public Awareness and Use of German Physician Ratings Websites: Cross-Sectional Survey of Four North German Cities. J Med Internet Res 2017 Nov 09;19(11):e387 [FREE Full text] [doi: 10.2196/jmir.7581] [Medline: 29122739]

58. Wang RY, Strong DM. Beyond Accuracy: What Data Quality Means to Data Consumers. Journal of Management Information Systems 2015 Dec 11;12(4):5-33. [doi: 10.1080/07421222.1996.11518099]

59. Knight S, Burn J. Developing a Framework for Assessing Information Quality on the World Wide Web. Informing Sci J 2005;8:159-172. [doi: 10.28945/493]

60. Barnes S, Vidgen R. An integrative approach to the assessment of e-commerce quality. J Electron Commerce Res 2002;3(3):114-127.

61. Park C, Kim Y. Identifying key factors affecting consumer purchase behavior in an online shopping context. 2003 Jan;31(1):16-29. [doi: 10.1108/09590550310457818]

62. Filieri R, Alguezaui S, McLeay F. Why do travelers trust TripAdvisor? Antecedents of trust towards consumer-generated media and its influence on recommendation adoption and word of mouth. Tourism Management 2015 Dec;51:174-185. [doi: 10.1016/j.tourman.2015.05.007] 
63. Kahn MG, Raebel MA, Glanz JM, Riedlinger K, Steiner JF. A pragmatic framework for single-site and multisite data quality assessment in electronic health record-based clinical research. Med Care 2012 Jul;50 Suppl:S21-S29 [FREE Full text] [doi: 10.1097/MLR.0b013e318257dd67] [Medline: 22692254]

64. Yaari E, Baruchson-Arbib S, Bar-Ilan J. Information quality assessment of community generated content: A user study of Wikipedia. Journal of Information Science 2011 Aug 15;37(5):487-498. [doi: 10.1177/0165551511416065]

65. Liberati A, Altman DG, Tetzlaff J, Mulrow C, Gøtzsche PC, Ioannidis JP, et al. The PRISMA statement for reporting systematic reviews and meta-analyses of studies that evaluate health care interventions: explanation and elaboration. J Clin Epidemiol 2009 Oct;62(10):e1-34 [FREE Full text] [doi: 10.1016/j.jclinepi.2009.06.006] [Medline: 19631507]

66. Moher D, Liberati A, Tetzlaff J, Altman DG, PRISMA Group. Preferred reporting items for systematic reviews and meta-analyses: the PRISMA statement. PLoS Med 2009 Jul 21;6(7):e1000097 [FREE Full text] [doi:

10.1371/journal.pmed.1000097] [Medline: 19621072]

67. Shine D. Risk-adjusted mortality: problems and possibilities. Comput Math Methods Med 2012;2012:829465 [FREE Full text] [doi: $10.1155 / 2012 / 829465]$ [Medline: 22474540]

68. Krumholz HM, Lin Z, Drye EE, Desai MM, Han LF, Rapp MT, et al. An Administrative Claims Measure Suitable for Profiling Hospital Performance Based on 30-Day All-Cause Readmission Rates Among Patients With Acute Myocardial Infarction. Circ Cardiovasc Qual Outcomes 2011 Mar;4(2):243-252. [doi: 10.1161/circoutcomes.110.957498]

69. Daskivich T, Houman J, Fuller G, Black J, Kim H, Spiegel B. Online physician ratings fail to predict actual performance on measures of quality, value, and peer review. J Am Med Inform Assoc 2018 Apr 01;25(4):401-407. [doi: 10.1093/jamia/ocx083] [Medline: 29025145]

70. Trehan SK, Nguyen JT, Marx R, Cross MB, Pan TJ, Daluiski A, et al. Online Patient Ratings Are Not Correlated with Total Knee Replacement Surgeon-Specific Outcomes. HSS J 2018 Jul;14(2):177-180 [FREE Full text] [doi: 10.1007/s11420-017-9600-6] [Medline: 29983660]

71. Emmert M, Adelhardt T, Sander U, Wambach V, Lindenthal J. A cross-sectional study assessing the association between online ratings and structural and quality of care measures: results from two German physician rating websites. BMC Health Serv Res 2015 Sep 24;15:414 [FREE Full text] [doi: 10.1186/s12913-015-1051-5] [Medline: 26404452]

72. Savović J, Weeks L, Sterne JA, Turner L, Altman DG, Moher D, et al. Evaluation of the Cochrane Collaboration's tool for assessing the risk of bias in randomized trials: focus groups, online survey, proposed recommendations and their implementation. Syst Rev 2014 Apr 15;3:37 [FREE Full text] [doi: 10.1186/2046-4053-3-37] [Medline: 24731537]

73. Kitchenham B, Charters S. Guidelines for performing Systematic Literature Reviews in Software Engineering. Technical Report EBSE 2007-001, Keele University and Durham University Joint Report. 2007. URL: https://userpages.uni-koblenz.de/ laemmel/esecourse/slides/slr.pdf [accessed 2020-09-19]

\author{
Abbreviations \\ AQ: accessibility data quality \\ CQ: contextual data quality \\ e-WOM: electronic word of mouth \\ GDPR: General Data Protection Regulation \\ IQ: intrinsic data quality \\ PRW: physician-rating website \\ RQ: representational data quality
}

Edited by T Kool; submitted 19.08.19; peer-reviewed by S Bidmon, R Terlutter, B Ranard; comments to author 08.10.19; revised
version received 24.04.20; accepted 13.08.20; published 28.09.20
Please cite as:
Mulgund P, Sharman R, Anand P, Shekhar S, Karadi P
Data Quality Issues With Physician-Rating Websites: Systematic Review
J Med Internet Res 2020;22(9):e15916
URL: $\underline{\text { http://www.jmir.org/2020/9/e15916/ }}$
doi: $\underline{10.2196 / 15916}$
PMID: $\underline{32986000}$

CPavankumar Mulgund, Raj Sharman, Priya Anand, Shashank Shekhar, Priya Karadi. Originally published in the Journal of Medical Internet Research (http://www.jmir.org), 28.09.2020. This is an open-access article distributed under the terms of the Creative Commons Attribution License (https://creativecommons.org/licenses/by/4.0/), which permits unrestricted use, distribution, and reproduction in any medium, provided the original work, first published in the Journal of Medical Internet Research, is 
properly cited. The complete bibliographic information, a link to the original publication on http://www.jmir.org/, as well as this copyright and license information must be included. 